\title{
Shakespeare en México
}

$\mathbf{F}^{\mathrm{N}}$ los últimos doce meses el acontecimiento shakesperiano en México, ha sido la representación de Romeo y Julieta, en la sala de espectáculos del Palacio de Bellas Artes, de la capital, que coincidió con la Exposición de Escenografía Mexicana Contemporánea, a fines de marzo. Fernando Wagner, el director de escena, aprovechó el concurso de alumnos del Instituto Nacional de Bellas Artes, y la colaboración del dibujante y decorador Julio Prieto y del poeta y crítico Xavier Villaurrutia, habiendo estilizado la traducción que se debe al escritor español Luis Astrana Marín (edición de M. Aguilar, Madrid, 1947). Se procuró que la interpretación fuese lo más realista, dentro de lo posible, y de acuerdo con ese propósito fueron reducidos a cuatro los doce escenarios originales y se hizo lo mismo con las decoraciones. La preparación del vestuario fué más fácil tarea, $\mathrm{y}$ respecto a la iluminación -dice González Casanova- 1 "en la escena de la cripta se hizo una innovación en cuanto al juego de las luces, porque contra lo acostumbrado, se proyectaron de atrás hacia adelante, lográndose a la perfección los efectos de penumbra y nebulosidad requeridos".

Carlos González Peña ${ }^{2}$ dió su parecer sobre dicha representación, así : “. . . en su exterioridad, deslumbradora y magnífica ; ... en cuanto al valor interpretativo, un poco apresurada, un tanto prematura, aunque interesante". Al hablar de la obra puntualizó: "El Romeo y Julieta de Shakespeare es primaveral y representa, justamente, la primera de su genial creador", afirmando también que es "la mảs difícil de verter a lengua extranjera"; y añadía: "Magistral es la coordinación de la trama en esa tragedia sin par; viva y honda la realidad de los caracteres; inagotable la vena poética que sustenta el 
diálogo. Encadénanse las escenas con gradación admirable; el asunto se desarrolla y dirige a su natural término con tan extraordinaria rapidez y precisión, que el interés no decae. Es Romeo y Julieta una. obra perfecta; acaso la más perfecta dentro de la habitual perfección de Shakespeare. Ya, al componerla, el joven estaba maduro, y Shakespeare era Shakespeare". En su ensayo, González Peña traza sintéticamente la historia de la tragedia y la explica al lector que no está iniciado.

Se quiso de tal modo celebrar el advenimiento de la Primavera. en una ciudad que le sirve a ésta de espléndido trono; y también fué escogida, para representarla, La fierecilla domada, que dirigió Seki Sano, aprovechando la misma traducción de Astrana Marín, e introdujo "un personaje de la Commedia dell'arte, Arlecchino, que Shakespeare imaginó necesario para su comedia". ${ }^{3}$

Al comentar la representación de Romeo y Julieta escribió Mauricio Magdaleno: 4 "A decir verdad, sólo nuestra época está en aptituđ' de representar a Shakespeare, porque tiene hoy procedimientos técnicos". Beatriz Aguirre, que encarnó a Julieta, mereció unánimes. elogios. Un espectador, un hombre de la calle, dió a la publicidad su opinión: "Sonreiría el dramaturgo con su sonrisa inglesa y pensaría que la actuación leal, fresca y joven de estos artistas mexicanos, le teje una guirnalda de mayo". ${ }^{5}$

Los festejos shakespereanos dieron motivo a la reproducción de un fragmento de Romeo y Julieta, en verso, por el poeta mexicano Manuel María Flores, uno de los representantes del romanticismo en el siglo $\mathrm{xrx} ;{ }^{6} \mathrm{y}$ de algunos comentarios para orientar al público, por ejemplo, el del Servicio Latinoamericano BBC, al anunciar que en breve presentaría a los radioescuchas una apreciación crítica con algunos extractos de Otelo. ${ }^{7}$

Al divulgarse la noticia de que en este año aparecería en España una nueva versión de Hamlet, fueron reproducidos en el Diario de Yucatán (Mérida) - que tiene uno de los mejores suplementos dominicales en la América Hispánica-, dos artículos de primer orden para la bibliografía shakespereana: uno de don Jacinto Benavente ${ }^{8}$ y otro de don Luis Calvo. ${ }^{9}$

Estas breves noticias son la demostración del interés que en México han tenido quienes gustan del teatro de tablas, por la obra del dramaturgo incomparable. Los más respetables críticos mexica- 
nos - Ignacio Manuel Altamirano, Manuel Gutiérrez Nájera, por ejemplo- han sido fervorosos animadores de esa admiración hacia quien es uno de los poetas que nos dan la poesía de cada día, el pan de nuestro espíritu, por ser eterna.

\section{Rafael Heliodoro Valle}

\section{B I B L IOGRAFIA}

1. González Casanova, H. "La Exposición de Escenografía. Romeo y Julieta". Novedades, 10 abril.

2. González Peña, Cartos. "La inmortal pareja". El Unizersal, 7 abril.

3. Magaña Esquivel, Antonio. "La Semana de Shakespeare". El Nacional, 3 abril.

4. Magdaleno, Mauricio. "Romeo y Julieta en Bellas Artes". El Universal, 5 abri1.

5. Quiroz, Martín D. "¿Qué diría Shakespeare?" Excelsior, 6 mayo.

6. Flores, Manuer M. "Julieta" (versos). El Nacional, 24 abril.

7. "Shakespeare y Otelo". Mazatlán, 25 abril.

8. Benavente, Jacinto. "Hamlet". Diario de Yucatán, Mérida, 8 mayo.

9. Calvo, Lurs. "Hamlet en escena". Diario de Yucatán, 15 mayo. 
